\title{
Decreasing incidence of major amputations in people with diabetes
}

\author{
P.Holstein ${ }^{1}$, N. Ellitsgaard ${ }^{2}$, B. Bornefeldt Olsen ${ }^{3}$, V. Ellitsgaard ${ }^{2}$ \\ ${ }^{1}$ Copenhagen Wound Healing Centre, Bispebjerg Hospital, Copenhagen, Denmark \\ ${ }^{2}$ Department of Thoracic and Vascular Surgery L, Bispebjerg Hospital, Copenhagen, Denmark \\ ${ }^{3}$ Department of Orthopaedic Surgery M, Bispebjerg Hospital, Copenhagen, Denmark
}

\section{Abstract}

Aims/hypothesis. To assess the results of the strategy used in avoiding major amputations in patients with diabetes mellitus.

Methods. A retrospective study for the years 1981 to 1995 in a central district hospital in Copenhagen with a catchment area population of about 178,000.

Results. There were 463 major leg amputations and the incidence decreased from 27.2 to $6.9 / 100,000$ population $(75 \%)$. The decrease in patients with Type I (insulin-dependent) diabetes mellitus was from 10.0 to $4.1(59 \%)$ and in Type II (non-insulin-dependent) diabetes mellitus from 17.2 to $2.8 / 100,000$ people $(84 \%)$. Analysis showed that the diabetic population remained constant despite a considerable fall in the number of older people. During the study period infra-popliteal arterial bypass was introduced for the treatment of critical lower limb ischaemia and in diabetic patients the number of bypasses increased from zero to $13 / 100,000$ population. The total number of revascularisation procedures in people with diabetes increased from 2.6 to $19.2 / 100,000$ population. Moreover, a multidisciplinary diabetic foot clinic was established.

Conclusion/interpretation. A $75 \%$ reduction in the incidence of major amputations coincided with a sevenfold increase in revascularization procedures and the establishment of a multidisciplinary diabetic foot clinic suggesting these measures are important in the prevention of diabetic leg amputations. [Diabetologia (2000) 43: 844-847]

Keywords Amputation, diabetes, diabetic foot, diabetic gangrene, arterial reconstruction, multidisciplinary team.
In the St Vincent Declaration Action Programme 1992 [1] a number of 5-year targets were outlined, one being the intention to reduce by one-half the rate of lower limb amputation for diabetic gangrene. Considering the small amount of evidence at that time supporting this demand [2-7], it is surprising that a number of recent reports [8-16] to a large extent have fulfilled these requirements. The purpose of this paper is to document the incidence of major amputations in diabetic patients in a 15 -year period in relation to a series of improvements in therapeutic measures.

Received: 8 November 1999 and in revised form: 14 March 2000

Corresponding author: P.E. Holstein, MD, Copenhagen Wound Healing Centre, Bispebjerg Hospital, DK-2400 Copenhagen NV, Denmark

\section{Subjects and methods}

We examined the clinical records of patients who underwent major leg amputations for vascular disease including diabetes in Bispebjerg Hospital in the 15 years from 1981 to 1995. Loss of the limb was recorded in 1472 cases (amputations below the ankle-disarticulation level were not included). Of these $463(31 \%)$ were in people with diabetes whose data are listed in Table 1. Data from the files of patients undergoing revascularisation were used to document the vascular reconstruction activity.

Data for the population in Copenhagen were obtained from the Statistics Department of the Community of Copenhagen. The catchment area for amputations for Bispebjerg Hospital in the centre of Copenhagen had about 178,000 people in 1981 (Table 2). From 1992 the municipality of Copenhagen redefined its districts and this catchment area was reduced by about 36,000 people. This change has been corrected for by indicating the incidence of amputations and revascularisations per 100,000 population a year. 
Table 1. Data for 463 (final level) major amputations in people with diabetes

\begin{tabular}{llrll}
\hline & $n$ & $\begin{array}{l}\text { Mean age } \\
\text { (years) }\end{array}$ & $\begin{array}{l}\text { range } \\
\text { (years) }\end{array}$ \\
\hline Men & Type I & 82 & 66.3 & $47-85$ \\
Women & Type I & 65 & 72.4 & $45-90$ \\
Men & Type II & 188 & 71.7 & $56-88$ \\
Women & Type II & 128 & 75.2 & $59-93$ \\
\hline
\end{tabular}

Table 2. Population data for the catchment area

\begin{tabular}{lrcr}
\hline $\begin{array}{l}\text { Age } \\
\text { (years) }\end{array}$ & 1981 & $1987+l-$ & $1995+l-$ \\
\hline$<45$ & 87068 & $91980(+6 \%)$ & $106845(+16 \%)$ \\
$45-69$ & 58703 & $45727(-22 \%)$ & $39318(-14 \%)$ \\
$\geq 70$ & 32730 & $33605(+3 \%)$ & $28729(-15 \%)$ \\
total & 178501 & $171312(-4 \%)$ & $174892(+2 \%)$ \\
\hline
\end{tabular}

$+/-$ Increment/decrement

The Copenhagen City Heart study [17] was used to obtain data of the prevalence of diabetes. In this investigation the prevalence in Copenhagen was estimated by questionaire in an age-stratified population sample of 20,000 people aged 20 years or more drawn at random from the Copenhagen Population register. Data for 1981-1983 and 1995-1997 were available as relevant to our study. The data of these samples were used to recalculate the number of people with diabetes according to the age and sex distribution in the catchment area.

\section{Results}

Incidence of amputations. Of the 463 final level amputations in diabetic patients $398(86 \%)$ were done in patients admitted from their own home. The other 65 were in patients admitted from chronic wards. The number of major amputations in people with diabetes decreased from 27.2 to 6.9 per 100,000 population $(75 \%)$ (Fig. 1). In patients from chronic wards the incidence was constant at about 2.8/100,000 population. These data are shown because people in longstay institutions in the centre of Copenhagen are rarely suitable for limb salvage revascularisation primarily because of mental organic syndromes. Subsequently the main result of this study is that in patients admitted from home the incidence of major amputations decreased from 25.6 to 4.8 per 100.000 population $(81 \%)$.

Major decrements in the number of amputations in patients with diabetic foot problems correlate with the increasing use of infra-popliteal bypass reconstructions initiated in 1987 as well as the establishment of a multidisciplinary diabetic foot centre in 1993 in the department of vascular surgery (Fig. 2). The team included vascular surgeons, diabetologists, specially trained nurses, an orthopaedic surgeon, chiropodists and an orthopaedic shoemaker. The results of the multifactorial treatment have been reported

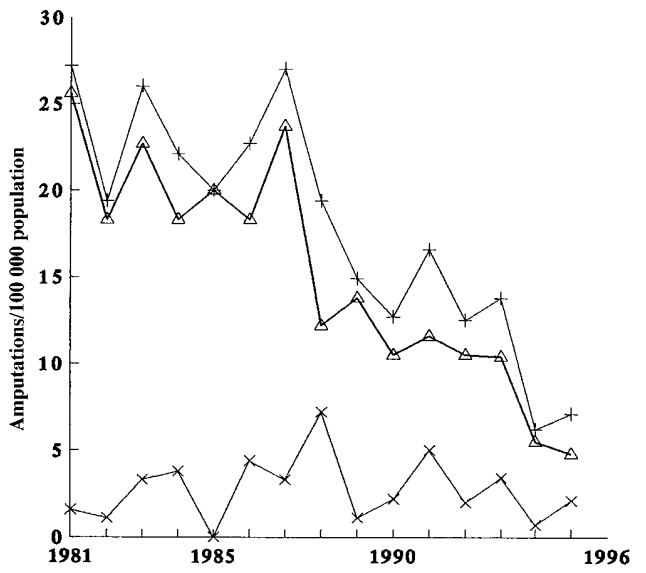

Fig. 1. Falling incidence of major amputations in people with diabetes. $\triangle$ patients admitted from home, $\rightarrow$ patients admitted from chronic wards, $\_+$total

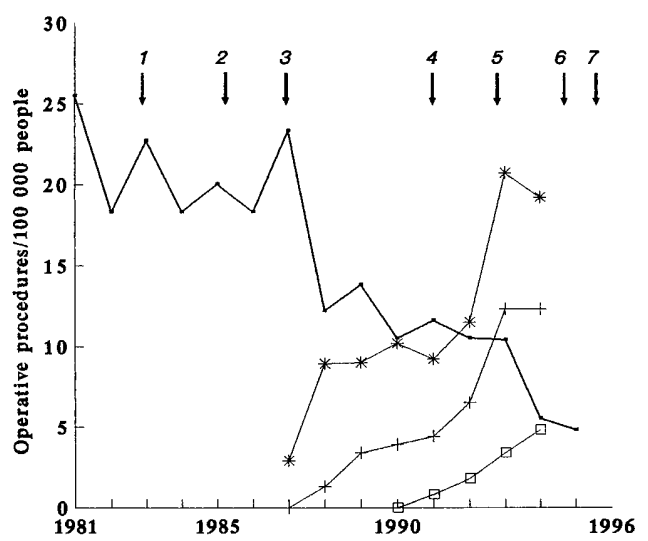

Fig. 2. Developement in treatment and organisation: (1) vascular surgery become a surgical speciality in Denmark, (2) specialised vascular clinic established, (3) application of infrapopliteal arterial reconstructions, (4) surveillance with Doppler-ultrasound graft scanning introduced, (5) multidisciplinary centralised diabetic foot clinic established in the vascular clinic, (6) Vascular surgery activity transferred to another hospital and (7) Further reorganisation of the hospital system with changed catchment areas for amputations. $\longrightarrow$ arterial reconstruction for critical ischaemia, $\_+$infra-popliteal arterial reconstruction to tibial and foot arteries, - major amputations, $\square \square$ graft revisions

in detail previously [18]. The number of graft revisions, not included in the total number of revascularisation procedures, are shown separately. These procedures were initiated in 1991 as a consequence of a triplex ultrasound scanning surveillance programme and increased to $4.8 / 100,000$ population. No vascular surgery data from 1995 is given because in that year the activity was transferred to a centralised vascular unit. Moreover, it has not been possible to analyse the number of amputations from 1996 and onwards because the hospital system, including the catchment areas, in the City of Copenhagen was reorganised in that period. 


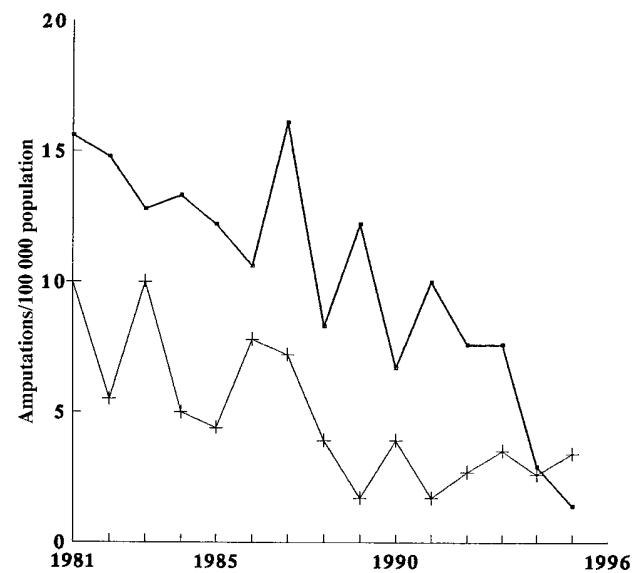

Fig.3. Falling incidence of major amputations in people with Type I ( $\_$) and Type II ( --$)$diabetes

There was a decrease in amputations per 100,000 population in patients with Type I [from 10.0 to 4.1 $(59 \%)$ ] as well as patients with Type II [from 17.2 to $2.8(84 \%)]$ diabetes. In patients admitted from home, i.e. excluding patients from chronic wards, the reduction in Type I diabetic patients was from 10.0 to $3.4(66 \%)$ and in Type II diabetic patients from 15.6 to $1.4(91 \%)$.

During the period studied there was also a decrease in amputations in people with lower limb occlusive arterial disease without diabetes from 50.5 to $21.4 / 100,000$ population (58\%) and in people admitted from home from 42.2 to $17.4 / 100,000$ population $(59 \%)$.

Population data. The number of inhabitants in the catchment area was almost constant with a decrease of $2 \%$ throughout the period studied (Table 2). The number of inhabitants in relevant age groups are shown for the years 1981,1987 and 1995 and the increments or decrements for the periods are shown in per cent. From 1987 to 1995, when the incidence of amputations decreased dramatically, the number of inhabitants over 45 years of age undergoing amputation decreased by about $15 \%$. This perhaps explains about $15 \%$ of the decrease in the amputation rate in non-diabetic patients.

There was, however, an increasing prevalence of diabetes during the two periods investigated (Table 3). In spite of the decrease in the number of elderly people, the total number of diabetic patients decreased by only 70 (3\%) for the whole 15 years studied and the prevalence of people with clinically recognised diabetes remained at about $1.6 \%$. The major reduction in amputations in diabetic patients could therefore not be explained by diabetes. The rate of amputations per 1000 patients with clinically recognised diabetes decreased from 17.3 to 4.3.
Table 3. Number of patients with diabetes in the catchment area

\begin{tabular}{|c|c|c|c|c|c|}
\hline \multicolumn{2}{|c|}{ Age (years) } & \multicolumn{2}{|c|}{ 1981-1983 } & \multicolumn{2}{|c|}{ 1995-1997 } \\
\hline & & $\%$ & $n$ & $\%$ & $n$ \\
\hline \multirow[t]{3}{*}{$20-44$} & women & 0.2 & 58 & 0.4 & 168 \\
\hline & men & 0.6 & 210 & 0.6 & 265 \\
\hline & women & 2.1 & 604 & 2.1 & 414 \\
\hline $45-69$ & men & 3.7 & 889 & 4.7 & 897 \\
\hline \multirow[t]{2}{*}{$\geq 70$} & women & 3.0 & 483 & 3.9 & 649 \\
\hline & men & 5.5 & 596 & 7.1 & 543 \\
\hline \multicolumn{2}{|l|}{ Total } & & 2840 & & 2935 \\
\hline total & $\geq 45$ years & & 2572 & & 2502 \\
\hline
\end{tabular}

$\%=$ percentage of the age group with diabetes

$n=$ number of people with diabetes

\section{Discussion}

In recent years an increasing number of studies have found a decrease in the incidence of major amputations in diabetic patients [2-16]. In patients with arterial disease without diabetes moderate reductions have been reported in some studies $[10,11,12,16$, 19-22]. The incidence of major amputations can vary greatly from one year to another. To claim an improvement in the prognosis for legs it is therefore important that a falling incidence of amputations is sustained over a number of years. This is shown in only a few studies [11, 14, 15], as well as in this study. One study that analysed nationwide figures found a $28 \%$ decrease of all vascular amputations from 1983 to 1990 [11]. In diabetic patients the decrease was $40 \%$ from 1982 to 1993 [15]. Another study [14] found a decrease in diabetes amputations in diabetic patients of $78 \%$ over 12 years, i.e. figures close to ours.

The decline in amputations might in theory result from a falling incidence of critical limb ischaemia, which increases with increasing age and in the presence of diabetes. In the above studies $[11,14,15]$ the population changed towards higher numbers of elderly people. An increase in amputations was therefore to be expected, emphasising the importance of the reductions actually found. In the present study the number of elderly people decreased in Copenhagen in contrast to the rest of the country. This decrease in elderly people could explain some of the falling incidence of amputations in non-diabetic patients. The figures available for the prevalence of diabetes showed, however, that the number was almost constant during the period studied. Thus it is unlikely that population variations could explain the decrease in amputations in people with diabetes.

The prevalence of people with clinically recognised diabetes in the early 1990 s was about $2 \%$ in Denmark [15]. In the region we studied the prevalence was about $1.6 \%$, which could be ascribed to using questionaires and to the age and sex composition 
of the groups. The true prevalence of people with diabetes is probably now about $4 \%$ of the population. To indicate the incidence of amputations per 100,000 population, as used predominantly in our study, is consequently more accurate than to indicate the incidence per 1000 diabetic patients, unless the population is screened regularly for diabetes.

The establishment of a centralised multidisciplinary team with a rapid service for diabetic foot problems is considered a major improvement in strategy because the referral procedure for patients with diabetic foot problems becomes well defined with the important possibility of avoiding delay. Thus the limb salvage at 1 month in patients with severe foot infection was $98 \%$; the number of revascularisations doubled with a 1-month limb salvage of $95 \%$ as documented in detail previously [18]. It is also highly likely that the multidisciplinary approach resulted in an improvement in prophylacsis, regulation of glycaemia and control of diabetic complications, which could easily have favourably influenced the number of amputations but we have no data to confirm this assumption.

Separate data for falling incidences of amputations in Type I and Type II diabetic patients have been documented previously in only one report [15]. This nationwide study over 7 years suggested that the decrease was caused by a decline in Type I diabetic patients only. Our study shows a major reduction in Type I as well as in Type II patients.

The leg amputations in diabetic people in the beginning of the period studied numbered about $27 / 100,000$ population, i.e. higher than most published incidences [23] and four times higher than the average for the whole country [15]. At the end of the study the incidence had decreased to about $7 / 100,000$ population, which is favourable compared with reported figures [23] and similar to the average nationwide figure of about $8 / 100,000$ population [15].

Our report documents a substantial decrease in the incidence of major amputations in people with Type I as well as those with Type II diabetes. The decrease coincides with increased revascularisation activity and the establishment of a multidisciplinary diabetic foot clinic suggesting these measures are important in the prevention of major amputations.

\section{References}

1. Krans HM, Porta M, Keen H (1992) Diabetes care and research in Europe: The St Vincent Declaration Action Programme. WHO, Regional office for Europe and international Diabetes Federation Europe. Copenhagen, Denmark, p. 8

2. Davidson JK, Alogna M, Goldsmith M, Borden J (1991) Assessment of program effectiveness at Grady Memorial Hospital - Atlanta. In: Steiner G, Lawrence PA (eds) Educating diabetic patients. New York, Springer Verlag, pp. 329-348
3. Lindegaard P, Jonsson B, Lithner F (1984) Amputations in diabetic patients in Gotland and Umeå counties 1971-1980. Acta Med Scand [Suppl] 687: 89-93

4. Assal JP, Muhlhauser I, Pernat A, Gfeller R, Jorgens V, Berger M (1985) Patient education as the basis for diabetes care in clinical practice. Diabetologia 28: 602-613

5. Edmonds ME, Blundell MP, Morris ME, Maelor Thomas E, Cotton LT, Watkins PJ (1986) Improved survival of the diabetic foot: the role of a specialized diabetic foot clinic. QJM 60: 763-771

6. Malone JM, Snyder M, Anderson G, Berhard VM, Holoway GA, Bunt TJ (1989) Prevention of amputation by diabetic education. Am J Surg 159: 520-524

7. Falkenberg M (1990) Metabolic control and amputations among diabetics in primary health care - a population-based intensified programme governed by patient education. Scand J Prim Health Care 8: 25-29

8. Griffiths GD, Wieman T (1992) Meticulous attention to foot care improves the prognosis in diabetic ulceration of the foot. Surg Gynecol Obstet 174: 49-51

9. LoGerfo FW, Gibbons GW, Pomposelli FB Jr et al. (1992) Trends in the care of the diabetic foot. Expanded role of arterial reconstruction. Arch Surg 127: 617-620

10. Pedersen AE, Olsen BB, Krasnik M et al. (1994) Halving the number of leg amputations: the influence of infrapopliteal bypass. Eur J Vasc Surg 8: 26-30

11. Ebskov LB, Schroeder TV, Holstein P (1994) Epidemiology of leg amputations. The influence of vascular surgery. Br J Surg 81: 1600-1604

12. Luther M (1994) The influence of arterial reconstruction surgery on the outcome of critical leg ischaemia. Eur $\mathbf{J}$ Vasc Surg 8: 682-689

13. Bakker K, Dooren J (1994) Een gespecialiseerde voetenpolikliniek voor diabetespatienten vermindert het aantal amputaties en is kostenbesparend. Ned Tijdschr Geneeskd 138: 565-569

14. Larsson J, Apelqvist J, Agardh C-D, Stenstrom A (1995) Decreasing incidence of major amputation in diabetic patients - a consequence of a multidisciplinary foot care team approach? Diabet Med 12: 770-776

15. Ebskov B, Ebskov LB (1996) Major lower limb amputations in diabetic patients: development during 1982 to 1993. Diabetologia 39: 1607-1610

16. Holstein P, Ellitsgaard N, Sørensen S et al. (1996) The number of amputa tions has decreased. Nord Med 111: 142-144

17. The Copenhagen City Heart Study 1989. Østerbroundersøgelsen. Ed. M. Appleyard. Scand J Soc Med 170: 41, p. 31

18. Holstein P, Sørensen S (1999) Limb salvage experience in a multidisciplinary diabetic foot unit. Diabetes Care 22: [Suppl 2]: B97-B103

19. Eickhoff JH (1993) Changes in the number of lower limb amputations during a period of increasing vascular surgical activity. Results of a nation-wide study, Denmark 1977-1990. Eur J Vasc Surg 159: 469-473

20. Lindholt JS, Bøvling S, Fasting H, Henneberg EW (1994) Vascular surgery reduces the frequency of lower limb major amputations. Eur J Vasc Surg 8: 31-35

21. Pell JP, Fowkes FG, Ruckley CV, Clarke J, Kendrick S, Boyd JH (1994) Declining incidence of amputations for arterial disease in Scotland Eur J Vasc Surg 8: 602-606

22. Karlstrøm L, Bergqvist D (1997) Effects of vascular surgery on amputation rates and mortality. Eur J Vasc Endovasc Surg 14: 273-283

23. Larsson J, Apelqvist J (1995) Towards less amputations in diabetic patients. Incidence, causes, cost, treatment and prevention - a review. Acta Orthoped Scand 66: 181-192 